\title{
PLANEJAMENTO DE CENÁRIOS E AMPLIFICAÇÃO DA VARIABILIDADE DA DEMANDA
}

\author{
Marina Dais de Faria \\ marinafaria86@hotmail.com \\ Universidade Federal do Rio de Janeiro - Rio de Janeiro, RJ/Brasil \\ José Luis Felicio dos Santos de Carvalho \\ zkcarvalho@hotmail.com \\ Universidade Federal do Rio de Janeiro - Rio de Janeiro, RJ/Brasil
}

Recebido em 27/10/2009

Aprovado em 29/03/2011

Disponibilizado em 01/12/2011

Avaliado pelo sistema double blind review

Revista Eletrônica de Administração

Editor: Luís Felipe Nascimento

ISSN 1413-2311 (versão on-line)

Editada pela Escola de Administração da Universidade Federal do Rio Grande do Sul.

Periodicidade: Quadrimestral

Sistema requerido: Adobe Acrobat Reader.

\section{RESUMO}

Este caso para ensino foi elaborado a partir dos problemas enfrentados pela DELTA, líder no mercado brasileiro de controle de pragas urbanas, a partir da epidemia de dengue do verão de 2007/2008, quando as vendas de inseticidas e repelentes pelos players do setor atingiram volumes significativamente superiores às expectativas. Falhas na previsão de demanda causaram escassez de produtos nos pontos de venda, desgastes no relacionamento da empresa com seus revendedores, dificuldades nas unidades de produção e também perda de participação de mercado da DELTA e da vice-líder GAMA para marcas alternativas. A natureza dos problemas levantados sugere questionamentos que envolvem a estrutura da indústria e a constituição da arena do mercado, bem como decisões de governança, gestão e gerência envolvidas na configuração do próprio negócio. Construída a partir de dados coletados por meio de pesquisa bibliográfica, investigação documental e técnicas de observação direta, a narrativa se desdobra a partir das idéias de incerteza, transformação organizacional e integração, proporcionando possibilidades de aproveitamento do caso em disciplinas de Estratégia, Marketing, Produção e Ética, preferencialmente em cursos de graduação ou em matérias básicas de programas de pós-graduação.

Palavras-Chave: Gestão de Estoques. Previsão de Vendas. Incerteza Ambiental. Dengue. 
Planejamento de cenários e amplificação da variabilidade da demanda

\title{
PLANNING SCENARIOS AND AMPLIFICATION OF VARIABILITY DEMAND
}

\begin{abstract}
This case was based on the problems facing the Delta, a leader in the Brazilian urban pest control, from the dengue epidemic in the summer of 2007/2008, while sales of insecticides and repellants by industry players reached volumes significantly higher than expectations. Failures in forecasting demand caused shortages of products to sell, wear the company's relationship with its dealers, difficulties in production and also loss of market share from DELTA and GAMMA deputy leader for alternative brands. The nature of the problems suggests questions involving the structure of industry and the establishment of the marketing arena, as well as decisions on governance, administration and management involved in setting up own business. Constructed from data collected through literature review, desk research and direct observation techniques, the narrative unfolds from the ideas of uncertainty, organizational transformation and integration by providing opportunities for exploiting the case in disciplines of Strategy, Marketing, Production and Ethics, preferably at the graduate level or raw materials of post-graduation.
\end{abstract}

Keywords: Inventory Management. Sales Forecast. Environmental Uncertainty. Dengue.

\section{Parte 1 - Apresentação do caso}

\subsection{Um zumbido desagradável}

Ao retirar o carro da garagem de casa, ainda tonto pelo zumbido do despertador, Marcelo Roldan vislumbrou o relógio que marcava seis horas da manhã. Preocupado, ele sabia que hoje ia ser um longo dia, em que participaria da primeira reunião de planejamento da próxima temporada na empresa. Como sempre, Marcelo passaria mais de 12 horas sentado naquela fria sala pintada num tom branco-hospital, com as grandes janelas esverdeadas debruçadas sobre um mundo confuso de automóveis e pessoas apressadas. Junto com sua equipe, ele analisaria exaustivamente as infindáveis planilhas e cansativas apresentações das temporadas passadas, como se nelas estivessem instruções detalhadas a respeito de como agir dali para frente.

Marcelo Roldan é gerente de marcas na companhia multinacional DELTA, e naquele dia participaria de uma reunião para decidir quais seriam as estratégias gerais para a linha de inseticidas e repelentes mantidas pela corporação no Brasil para a próxima temporada. Chegando à sede da empresa, Marcelo dirigiu-se diretamente à sala vazia e perturbadoramente silenciosa para os zumbidos de carros, gentes e insetos. Outra previsão de Marcelo se confirmava: depois de alguns momentos de serenidade fugaz, chegavam à sala Paulo Yotuel, o diretor de marketing, e Renata Ruzzo, gerente de vendas, assim como suas equipes.

Depois de seis horas de reunião e muitas xícaras de café amargo, quando os resultados do ano anterior já tinham sido exibidos, Renata levantou-se da cadeira e desfiou palavras 
Marina Dais de Faria \& José Luis Felicio dos Santos de Carvalho

proféticas: "Para mim a coisa é bem simples. Se tiver dengue esse ano eu garanto que tudo que for produzido será vendido!”. O assessor de vendas Alberto Machete mostrou menos entusiasmo: "Com os estoques formados pelos revendedores em função do medo de nova epidemia, não venderemos uma única unidade de produto caso haja dengue nos próximos meses. Por outro lado, como houve epidemia no último ano, de acordo com as previsões climáticas não vai haver dengue mesmo, então tanto faz. Estamos acabados.”. Waldir Havana, também assessor de vendas, retomou o otimismo: "O cliente não sabe se vai ter dengue. Aliás, nem nós sabemos, e ficamos na dependência do maldito El Niño. Seja como for, diante dessa incerteza a consumidora vai ficar com medo de que a epidemia do ano passado aconteça novamente e vai querer se proteger. Vamos esgotar os estoques atuais vender como nunca!".

As opiniões iam de um extremo a outro, motivando discussões que incluíam pragas voadoras, aquecimento de oceanos e, logicamente, falavam sobre o péssimo sabor do café servido na reunião. A despeito das janelas fechadas, parecia que mosquitos teimavam em atormentar os ouvidos de Marcelo Roldan. Considerando que as marcas de repelentes que estavam a seus cuidados constituíam o carro-chefe da empresa - e, portanto, todos na reunião tinham interesse naquelas decisões -, antes de vencer quaisquer mosquitos que o assombrassem, ele teria de reagir às opiniões discordantes dos colegas. Outras questões o empertigavam. Como gerenciar linhas de produtos das quais alguns consumidores dependem para evitar uma doença mortal? É possível estabelecer um planejamento efetivo de produção para itens cuja demanda não depende de métodos usuais de previsão? Como pensar estrategicamente um produto cujas características são tão complexas? No curto prazo, se as condições climáticas não ajudarem, como sobreviver num verão sem dengue? Todas essas questões refletiam a necessidade de pensar um planejamento de marketing e de produção para esse verão de 2008/2009.

\subsection{Os mosquitos atacam: a epidemia de 2007/2008}

Nas lembranças de Marcelo e Renata, ainda estavam bem frescas as imagens dos efeitos devastadores da dengue no Rio de Janeiro. Hospitais lotados, pessoas sendo atendidas pelos corredores, crianças vomitando sangue, tendas médicas do Exército configurando um campo de batalha montado contra um inimigo quase invisível. Os jornais noticiavam diariamente mais casos confirmados da doença, enquanto o número de óbitos crescia rapidamente. A certa altura, quase todos os cidadãos tinham - ou acreditavam ter - algum conhecido que tinha sido vitimado pelo mosquito. Junto com o pânico da população, veio a corrida às farmácias, na 
Planejamento de cenários e amplificação da variabilidade da demanda

busca de repelentes e outros produtos capazes de minimizar o risco de contrair a doença.

No verão de 2007/2008, o Brasil sofreu com os casos de dengue espalhados por todo o território, a região sudeste foi a mais afetada, representando $50 \%$ dos casos no país. O Rio de Janeiro foi a unidade federativa em que mais ocorrências foram registradas, com um aumento de $214 \%$ em relação ao verão anterior, o que causou alarde e elevou a consciência da população com relação à doença. Sob interferência dos órgãos governamentais, a dengue foi declarada epidêmica no Rio em março de 2008. O mosquito ceifou especialmente as vidas das crianças, a letalidade chegou a $20 \%$, valor cinco vezes superior ao aceito pela Organização Mundial de Saúde. Até abril de 2008, o número de casos registrados no Rio beirava 150 mil.

O sistema público de saúde não estava preparado para atender a tantas pessoas afetadas pela dengue e foi preciso estruturar um esquema especial para que todos os casos da doença fossem detectados, diagnosticados e tratados. As forças armadas foram convocadas para o combate à epidemia e a mídia passou a dar muita ênfase aos assuntos relativos à dengue. Todos os jornais e programas de televisão passaram a trazer reportagem a respeito de prevenção, sintomas e tratamento da dengue. À medida que o mosquito tornava-se senhor absoluto do noticiário, as pessoas procuravam meios para proteger suas famílias da dengue.

\subsection{Insetos, larvas e vírus}

A dengue é uma doença infecciosa de caráter endêmico-epidêmico, causada por um vírus e transmitida pelo mosquito Aedes (Stegomyia) aegypti - vetor também responsável pela transmissão da febre amarela urbana - e que ocorre principalmente em áreas tropicais e subtropicais. Responsáveis por mais de 25 mil mortes anuais em mais de 100 países, as epidemias geralmente ocorrem no verão, durante ou imediatamente após períodos chuvosos.

A erradicação da dengue é praticamente impossível, e não há vacina para a virose. Em ambiente propício e sem combate aos vetores, a doença tende à pandemia. Febre alta, dores de cabeça, no corpo e manchas avermelhadas na pele são alguns sintomas da dengue, os quais aparecem três dias depois da picada do mosquito. A ocorrência de formas hemorrágicas da doença tem sido explicada pela presença de anticorpos devido às infecções seqüenciais por diferentes sorotipos do vírus. Em tais condições, o quadro clínico agrava-se rapidamente, levando à insuficiência circulatória e, para 5\% dos enfermos, à morte em cerca de 24 horas.

Os relatos de epidemias de dengue são registrados desde 1846 no Brasil, e a elevada competência vetorial do Aedes aegypti, originário da África e bem adaptado ao ambiente urbano densamente povoado tornam a prevenção da dengue uma tarefa igualmente impossível 
de ser atingida com os atuais meios disponíveis. As medidas de controle objetivam eliminar o mosquito em suas diferentes fases; de modo geral, contudo, a efetividade dessas intervenções tem sido baixa, não conseguindo conter a disseminação do vírus e as epidemias se sucedem.

Considerando as recomendações contrárias ao uso de inseticidas em larga escala, em função da agressão ao meio ambiente quando tais produtos são aspergidos em massa em zonas urbanas, o Ministério da Saúde no Brasil tem estipulado orientações de cunho preventivo para as populações residentes nas áreas atingidas. Assim, a divulgação das formas de se evitar a dengue parece confiar essencialmente no combate aos focos de acúmulo de água, locais propícios para a reprodução do mosquito transmissor da doença. O governo patrocina informes na mídia, campanhas de propaganda e ações de fiscalização como formas de engajar a população nas atividades de prevenção. A ação governamental mais divulgada é o "Dia D Contra a Dengue", evento que ocorre pouco antes do início do verão e tem como objetivo informar a população a respeito de prevenção, sintomas e eventuais tratamentos.

Além das medidas coletivas de prevenção, muitas pessoas adotam medidas individuais. $\mathrm{O}$ recurso mais usual é a fabricação e/ou a aquisição de produtos que repelem ou matam os mosquitos, tais como ungüentos e preparados artesanais, inseticidas produzidos e comercializados em larga escala e, principalmente, repelentes de insetos. A despeito do alerta governamental de que a única medida eficaz para o combate à epidemia é a prevenção coletiva, as pessoas usam repelentes para manter os mosquitos longe de seus corpos e de seus familiares, guardando em suas residências inseticidas para matar os vetores da dengue.

\subsection{Clima bom para os mosquitos}

O verão apresenta as condições ideais para a proliferação dos mosquitos transmissores da febre dengue, haja vista que o calor e as chuvas, próprios dessa estação do ano, aumentam o metabolismo dos insetos. Deve-se acrescentar que alguns fenômenos naturais podem interferir na presença de insetos. O mais conhecido deles - em razão de sua grande influência nas condições climáticas - é El Nino, um fenômeno atmosférico-oceânico causado por alterações significativas na distribuição de temperaturas na superfície do setor centro-leste do Oceano Pacífico. Esse evento foi primeiramente reconhecido por pescadores sul-americanos, que o designaram em referência ao menino Jesus, por conta da coincidência do fenômeno com o período de Natal. El Nino costuma manifestar-se em intervalos médios de 4 anos e tem uma persistência de 6 a 15 meses, afetando as condições climáticas regionais e global. 


\section{Gráfico 1 - Casos de dengue no Brasil por região}

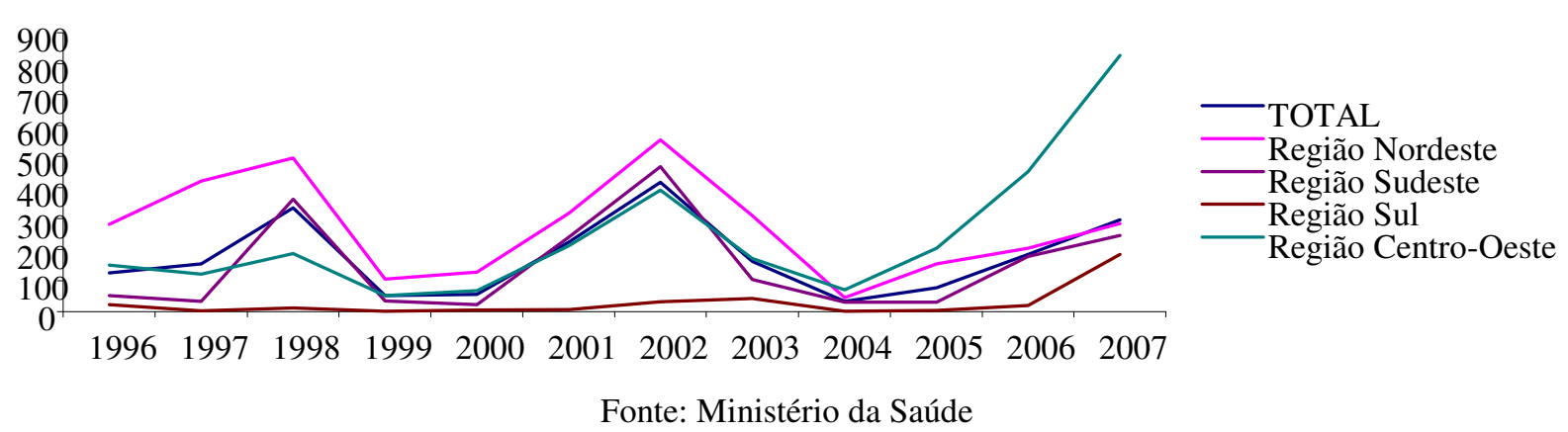

Como ainda não são conhecidas as causas do aquecimento do Oceano que dão nascimento a El Nino, não é possível fazer uma previsão exata do aparecimento do fenômeno. No entanto, diversos institutos de pesquisas meteorológicas monitoram constantemente a temperatura dos oceanos, sendo capazes de detectar as alterações antes que elas causem mudanças perceptíveis no clima global. No Brasil, El Niño causa diferentes impactos em cada região: no Norte e no Nordeste diminuem as precipitações; no Sul, no Sudeste e no Centro-Oeste ocorre aumento de temperatura e maior precipitação, condições ideais para a proliferação do Aedes aegypti.

Ao se considerar a evolução histórica dos casos de dengue no país, conforme acompanhamento realizado pelo Ministério da Saúde desde 1996, pode-se observar a ocorrência de picos da doença nos anos de 1998, 2002 e 2007, os quais coincidem com o surgimento de El Niño no Oceano Pacífico, como evidencia o Gráfico 1.

\subsection{O mercado de inseticidas e repelentes}

Os produtos indicados para controle de insetos costumam ser classificados em repelentes pessoais e inseticidas. Dentre os inseticidas, as principais linhas de produtos são: (1) os aerossóis, que têm ação instantânea e eficaz contra insetos voadores e rasteiros, podendo ser aplicados no ambiente ou diretamente no inseto; (2) os elétricos, que repelem os mosquitos sem matá-los, sendo indicado para uso noturno; (3) as iscas, que costumam ser utilizadas para controle de grandes infestações; (4) os líquidos, que podem ser aspergidos no ar por meio de bombas manuais; e (5) os espirais, que constituem a alternativa mais econômica para repelir mosquitos. Cada linha de produtos tem características peculiares no que tange a frequiência de compra, penetração de mercado e perfil de consumidores.

Existe uma grande diferença de penetração entre linhas de produtos por meio do 
Marina Dais de Faria \& José Luis Felicio dos Santos de Carvalho

percentual de lares brasileiros com algum produto para controle de pragas. Tal diferença faz com que as empresas atuantes nesse mercado tenham que adotar estratégias específicas para cada linha. Mesmo a penetração do aerossol, a maior dentre as linhas, ainda apresenta potencial de desenvolvimento, o que mostra que a categoria de produto de controle de pragas ainda tem muito a crescer, e para isso as empresas trabalham para aumentar a relevância da categoria. O repelente possui a menor penetração, o que faz com a DELTA, que é a líder de mercado, trabalhe no sentido de aumentar essa penetração e não somente seu market share .

Os diferentes perfis de consumidores de cada linha de produtos geram variações correspondentes na penetração de mercado de acordo com classe social - conforme mostra o Gráfico 2 - Um exemplo da diferença de perfil sócio-demográfico dos consumidores das linhas de produtos é a grande penetração nas classes A e B de aerossóis, elétricos e iscas, enquanto as opções de menor desembolso, como líquidos e espirais, apresentam maior penetração nas classes D e E.

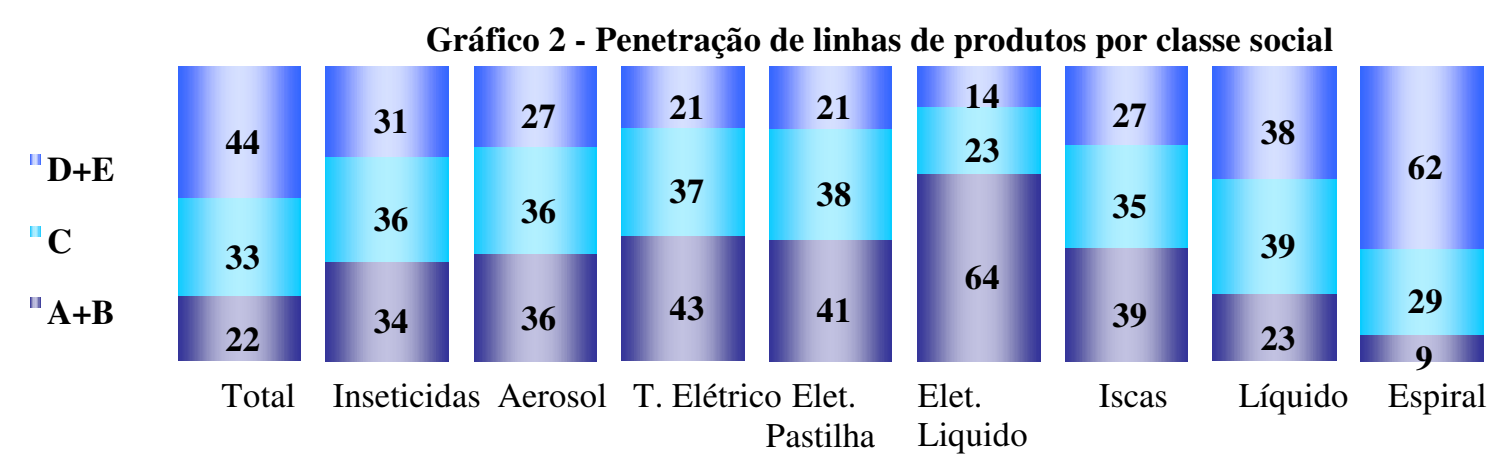

Fonte: Documentos internos da empresa DELTA

\subsection{A cliente e a batalha contra os mosquitos}

No que diz respeito ao uso de inseticidas, pode-se agrupar inicialmente os consumidores em duas grandes categorias: aqueles que utilizam o produto como forma de prevenção ao aparecimento de insetos e aqueles que usam o produto somente quando o inseto aparece. Além dessa primeira categorização, deve-se notar que existem pessoas que utilizam inseticidas somente contra insetos voadores - tais produtos parecem menos agressivos aos clientes - e pessoas que acham necessária a utilização desses produtos contra insetos rasteiros, principalmente baratas. Tais agrupamentos não são mutuamente excludentes, porém se pode verificar a tendência de que os consumidores pertençam preferencialmente a um deles.

De modo genérico, quem costuma comprar inseticidas e repelentes para uma residência é 
Planejamento de cenários e amplificação da variabilidade da demanda

a mulher, e por isso as empresas optam por focar seus esforços publicitários nas chamadas "donas de casa", chegando ao ponto de tratar o cliente médio sempre como "a cliente". Essas mulheres costumam comprar inseticidas principalmente em supermercados, embora as vendas em farmácias sejam muito significativas para os repelentes.

Para as consumidoras de inseticidas, a escolha de marcas específicas dentro da categoria de produtos depende de dois atributos: eficiência e segurança. Em geral os consumidores costumam perceber tais atributos como opostos, ou seja, produtos tidos como mais seguros tendem a ser considerados pouco eficientes, enquanto produtos vistos como eficientes são também vistos como muito agressivos à saúde dos seres humanos. Por essa mesma razão, as marcas procuram posicionar-se em função de uma "escala eficiência-segurança".

Os repelentes diferenciam-se dos inseticidas em alguns aspectos importantes na visão da cliente. As principais imagens associadas aos repelentes em grupos de foco conduzidos por agências de propaganda mostram que a linha de produtos encontra-se relacionada ao contexto outdoor: viagens, praia, mato, campo, acampamento, trilha. $\mathrm{O}$ contato com a natureza parece despertar a consciência sobre a necessidade do repelente. Estadias em áreas litorâneas são ocasiões para as quais o uso de repelentes costuma ser lembrado, pois a maior exposição do corpo exige proteção contra insetos. Em função da proliferação dos mosquitos e das vestimentas mais leves, o verão é o período do ano mais associado à linha, e as crianças constituem os principais usuários do produto, a partir da decisão de compra e uso das mães.

Proteção, liberdade, paz e tranqüilidade são sensações comumente associadas pelas consumidoras aos repelentes. Tais percepções advêm apenas do segmento de usuários da linha de repelentes; quando pesquisas semelhantes são conduzidas junto a não usuárias o resultado parece ser diferente, o que representa uma barreira para que as empresas possam atingir novos usuários. As não usuárias têm a percepção de que os repelentes têm cheiro desagradável e que podem ser prejudiciais, visto que constituiriam um veneno em contato com o corpo.

Há, no entanto, um ponto em relação ao qual todos os segmentos - homens, mulheres, usuários, não usuários, pessoas com filhos ou sem filhos - parecem compartilhar da mesma percepção: o repelente está diretamente ligado à idéia de viagens e de contato com a natureza, seja no campo ou na praia. Isso torna o uso esporádico, praticamente restrito a momentos de férias ou pausas na rotina. Poucos são os clientes que utilizam repelentes no dia-a-dia, de forma regular, dentro do ambiente doméstico, tornando pequena a freqüência de compra dessa linha de produtos. Quando há um uso mais freqüente de repelentes no contexto doméstico, isso em geral ocorre com pessoas alérgicas ou com filhos alérgicos a picadas de insetos, ou 
Marina Dais de Faria \& José Luis Felicio dos Santos de Carvalho

consumidores que residem em locais com forte infestação de insetos, principalmente pernilongos, ou seja, pessoas com motivação extra para se proteger das pragas.

Outro problema encontrado pelas empresas que atuam nesse mercado para favorecer o aumento da venda de repelentes são as soluções caseiras: dormir com ventilador ligado, fechar janelas a partir das 17 horas, colocar mosquiteiros nas janelas, usar citronela em vela ou em óleo, colocar lâmpada amarela no quarto, tomar vitaminas do complexo B. Apesar da total ineficiência da maioria dessas supostas soluções, a crença em sua capacidade de matar mosquitos, aliada à falta de recursos financeiros para comprar inseticidas ou repelentes, evidencia uma recorrente ameaça de substituição aos produtos comercializados pela indústria.

Os próprios inseticidas fabricados pelos players da indústria também se configuram como obstáculos para que o uso de repelente seja difundido. Em função de sua ação basear-se no extermínio das pragas e não em sua repulsa, para o dia-a-dia os inseticidas têm uma presença significativamente mais regular nas residências do que o repelente corporal. Ao contrário dos repelentes, a imagem dos inseticidas está fundamentada na idéia de capacidade de extermínio dos insetos.

Outro fator que prejudica a venda de repelentes envolve os pontos de venda, uma vez que os repelentes costumam ser expostos pelos varejistas ao lado dos inseticidas nas gôndolas. Tal medida aparentemente afugenta potenciais consumidores que tendem a enxergar o repelente como um produto demasiadamente tóxico para ser aplicado no corpo em função da proximidade com os inseticidas, naturalmente tidos como mais nocivos à saúde.

Diante desse cenário, a DELTA visa o aumento da penetração da categoria, ou seja, ao longo dos últimos anos a empresa dedica-se sistematicamente à busca de novos usuários, além de tentar elevar a freqüência de compra dos clientes atuais. Com vistas a cumprir essa meta, a empresa parece confiar nos próprios consumidores como maior fonte de informações. Essa posição pode ser justificada em função de que, no mercado de controle de pragas, as vendas aumentam de acordo com a percepção dos consumidores a respeito da incidência de insetos, isto é, pouco interessa se a presença de insetos constitui uma realidade palpável, o que realmente importa é que o consumidor perceba a existência desses insetos.

A partir de 2005, a DELTA passou a utilizar um serviço de atendimento ao consumidor (SAC) como principal meio para capturar as percepções dos consumidores a respeito da presença de insetos. Por intermédio das informações transmitidas pelo SAC, é possível traçar um panorama das regiões do país em que o consumidor percebe infestações de insetos. 
Planejamento de cenários e amplificação da variabilidade da demanda

\subsection{Os players do mercado brasileiro de controle de pragas}

O mercado de controle de pragas no Brasil é disputado por dois principais players no momento desse caso, as empresas DELTA e GAMA. A primeira, organização em que trabalha Marcelo Roldan, possui cinco marcas nessa família de produtos, sendo duas de repelentes e três de inseticidas. Uma das marcas de repelentes dessa empresa é líder de mercado e top of mind em todas as pesquisas com consumidores; a outra marca é de baixo desembolso. Dentre as marcas de inseticidas fabricadas pela DELTA, uma se posiciona como extremamente eficiente, outra como capaz de equilibrar eficiência e segurança, e a terceira como marca de preço baixo.

A empresa GAMA, também multinacional norte-americana com atuação no Brasil, assim como a DELTA, conta com uma marca de repelente e três de inseticidas, sendo uma delas reconhecida pelos consumidores como muito segura, enquanto outra vem se firmando como extremamente eficiente, e a terceira é a marca de preço baixo. A marca de repelente da GAMA vem ganhando espaço no mercado por ser considerada pelos consumidores como menos tóxica do que as marcas de repelente da DELTA. Note-se, adicionalmente, que existem poucas diferenças entre as fórmulas químicas dos agentes presentes nas marcas de uma mesma empresa, bem como nas marcas de uma empresa para outra. Com isso, as diferenças mais significativas são aroma, a embalagem, o nome e o posicionamento da marca. Em outras palavras o que importa nesse mercado é a percepção do consumidor.

Os dois principais players têm em comum o fato de serem empresas que fabricam e comercializam produtos de natureza variada, tais como fórmulas para tratamento de pisos e móveis, para limpeza de banheiros, para cuidado de automóveis e purificadores de ar. No que diz respeito a essas outras categorias de produto a GAMA possui marcas mais consolidadas no mercado do que as marcas da DELTA. Isso faz com que a GAMA tenha melhor relacionamento com os pontos de venda e consigo mais espaço para seus inseticidas nas prateleiras de super mercados e mercadinhos de bairro.

Outro ponto comum entre DELTA e GAMA advém de sua origem norte-americana: ambas desconhecem aspectos importantes do negócio no Brasil. Um desses aspectos envolve as endemias que atingem o terceiro mundo. Para entender melhor essas enfermidades, a DELTA criou uma "gerência de doenças" dentro da divisão de marketing da organização no Brasil, com funcionários trabalhando sob o comando do diretor Paulo Yotuel para obter informações a respeito de formas de transmissão e métodos de prevenção.

Além dessas duas principais empresas, muitas outras concorrem crescente mercado de 
Marina Dais de Faria \& José Luis Felicio dos Santos de Carvalho

controle de pestes. Algumas dessas organizações apresentam grande expressividade em mercados como os de alimentos e de higiene pessoal, e ainda disputam espaço no mercado de controle de pragas, em que as marcas mais antigas costumam ser vistas como mais confiáveis em função de terem tido sua segurança "aferida" ao longo dos anos pelos clientes. Deve-se destacar que várias pequenas empresas lançaram novas marcas - principalmente de repelentes - depois do surto de dengue de 2007/2008. Muitas dessas marcas são produzidas e comercializadas por empresas "de fundo de quintal" com alguma expertise em compostos fármaco-químicos, e as marcas que não tinham expressividade em vendas, ou mesmo não existiam, vêm ganhando espaço principalmente em razão do ganho de relevância da categoria.

\subsection{A cliente contra-ataca: alguns dados de vendas}

Em representações históricas de vendas anuais de inseticidas e repelentes, percebe-se claramente a sazonalidade atrelada à maior presença de insetos, determinada pelas estações mais quentes. O Gráfico 3 ilustra essa sazonalidade, evidenciando que o crescimento das vendas começa a ocorrer no mês de outubro e tem seu pico em janeiro e fevereiro.

Essa configuração de vendas ao longo do ano é modificada somente quando ocorre alguma mudança significativa no ambiente, como falta ou excesso de chuvas que interfiram nos ciclos reprodutivos dos insetos, ou na presença de mudanças econômicas, como uma crise financeira que faz com que as pessoas comprem menos inseticidas e repelentes. Como se observou ao longo das últimas subseções, a dengue influencia expressivamente a venda desses produtos, principalmente por aumentar a relevância da categoria. Por conta da ameaça de epidemia, as pessoas param de encarar os inseticidas e repelentes como produtos que matam insetos, e passam a considerá-los como produtos que previnem doenças.

Comparando os dados gerados pelas empresas acerca de vendas de inseticidas e repelentes com as informações do governo sobre a incidência de casos de dengue registrados, observa-se que nos anos com surtos mais significativos o mercado cresce além do usual, indicando a influência da doença nas vendas. $\mathrm{O}$ crescimento das vendas também pode ser creditado ao ganho de espaço da doença na mídia nacional, que influencia o número de pessoas com conhecimento da doença. Por si só, a dengue não para ser capaz de causar uma mudança de comportamento imediato nos consumidores, sendo necessária a divulgação de casos da doença e o alerta oficial acerca do perigo de epidemia. 
Planejamento de cenários e amplificação da variabilidade da demanda

Gráfico 3 - Volume de vendas no mercado de repelentes

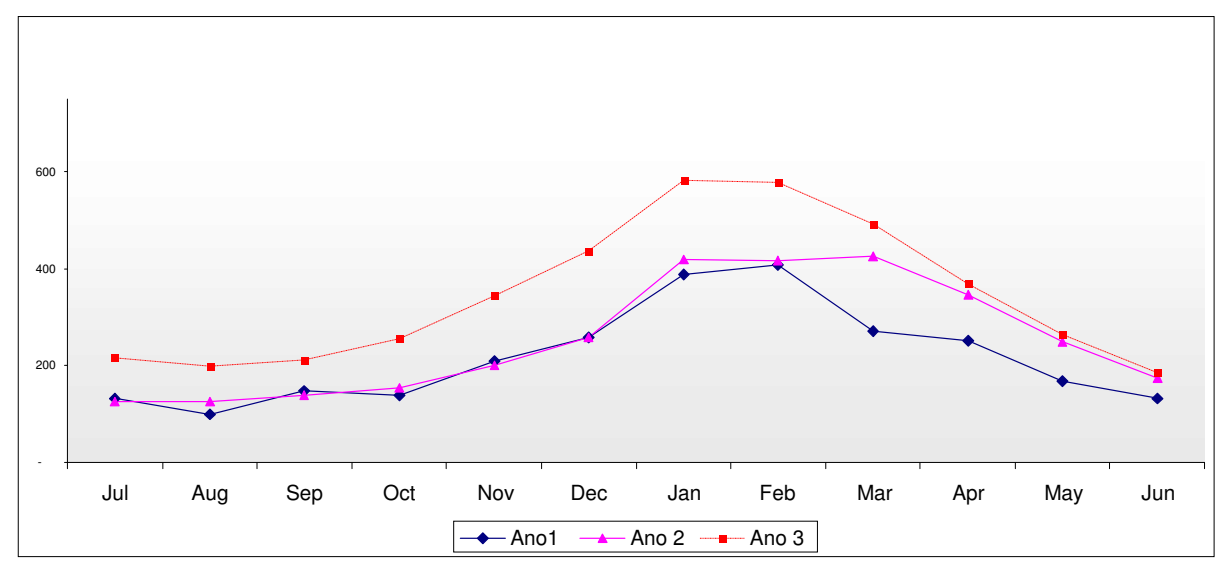

Fonte: Documentos internos da empresa DELTA

Ao se buscar traçar um paralelo entre a variação do número de casos de dengue e a venda de inseticida por regiões geográficas em 2007/2008, percebe-se sob outra perspectiva a influência da dengue na estrutura do mercado. Como se pode aferir a partir do Gráfico 4, nas regiões em que foram registrados expressivos aumentos de casos de dengue - Nordeste e Sudeste do Brasil - o mercado também cresceu.

Gráfico 4 - Casos de dengue no período 2007/2008 versus vendas de inseticidas e repelentes por região

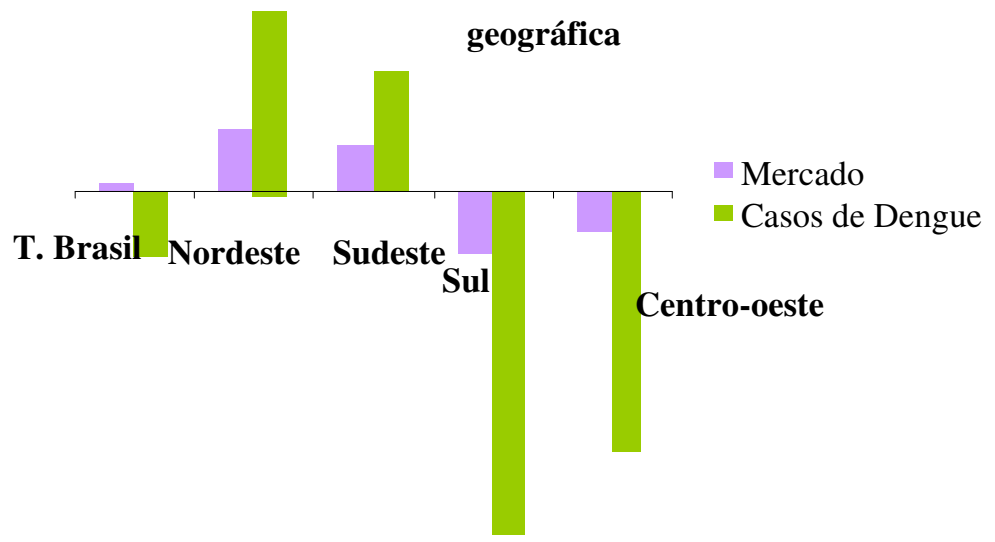

Fonte: Documentos internos da empresa DELTA

O crescimento das vendas no Sudeste brasileiro foi impulsionado principalmente pelo enorme aumento da demanda no Rio de Janeiro, onde ocorreu um aumento de $214 \%$ nos casos de dengue em comparação com os dados do período anterior. O governo declarou situação de epidemia em março de 2008, e durante aquele surto ocorreram diversos óbitos, principalmente de crianças. Como se viu na subseção 1.2, a letalidade da doença nesse período foi muito superior ao índice aceito pela OMS: até abril de 2008, o número de casos 
registrados no Rio chegava a 170 mil, com 149 mortes.

Deve-se registrar igualmente que o mercado parece responder mais expressivamente às situações críticas da doença, especialmente em razão de óbitos devidos à ocorrência de febre hemorrágica da dengue (FHD). Assim, o cenário caótico que se constituiu no Rio de Janeiro teve um impacto brutal na venda dos produtos de controle de pragas.

A epidemia do verão de 2007/2008 aumentou as vendas de todas as linhas de produtos, tanto de inseticidas quanto de repelentes, porém apenas a penetração de mercado dos repelentes sofreu aumento correspondente. Em outras palavras, no mercado de inseticidas não entraram novos compradores, somente os mesmos consumidores passaram a adquirir mais unidades; no mercado de repelentes, pessoas que não compravam passaram a comprar.

Em São Paulo, a despeito de uma redução de $96 \%$ no número de casos registrados da doença, houve uma grande preocupação dos consumidores, o que poderia explicar o aumento do mercado no início da temporada de 2008. Não aconteceu uma resposta imediata à ocorrência de casos de dengue em São Paulo, porém mesmo os menores registros de FHD foram capazes de propiciar mais compras na categoria de produtos.

\subsection{O verão da dengue e o pico nas vendas}

Com a epidemia de dengue no verão de 2007/2008, as vendas de produtos que agem matando ou repelindo mosquitos foram bruscamente afetadas. O Gráfico 5 mostra a curvapadrão de vendas de inseticidas e repelentes da DELTA para as temporadas de 2005/2006 (identificada como FY06) e 2006/2007 (FY07). Na curva do ano da epidemia de 2007/2008 (FY08) pode-se divisar o grande pico de vendas em abril.

O altíssimo volume de vendas no final do verão de 2008, completamente fora dos padrões anteriores, não era esperado pela empresa, provocando baixas aceleradas nos estoques e, por conseguinte, uma enorme escassez de produtos. Em diversos pontos de vendas, o consumidor procurava em vão pelas marcas de inseticidas e repelentes da DELTA. A deficiência no abastecimento fez com que os consumidores optassem por dar chance a outras marcas: o importante era obter um repelente para se proteger, e se a marca líder estava em falta, qualquer outra servia. Diante de tal cenário, surgiu uma profusão de marcas alternativas, produzidas por pequenos fabricantes, muitos dos quais eram empresas sem qualquer expressividade, que se impuseram devido ao inusitado desequilíbrio entre oferta e demanda.

Passado o surto, logo veio o óbvio diagnóstico da situação enfrentada pela DELTA durante o verão da dengue. Para que a falta de estoque tivesse sido evitada ou minimizada, 
Planejamento de cenários e amplificação da variabilidade da demanda

deveriam ter sido traçadas previsões de vendas que contemplassem o aumento de demanda ensejado pela explosão nas ocorrências de casos de dengue. Contudo, o real problema consiste na dificuldade para prever uma epidemia de proporções à que ocorreu em 2007/2008.

Gráfico 5 - Efeito da epidemia de dengue nas vendas de repelentes

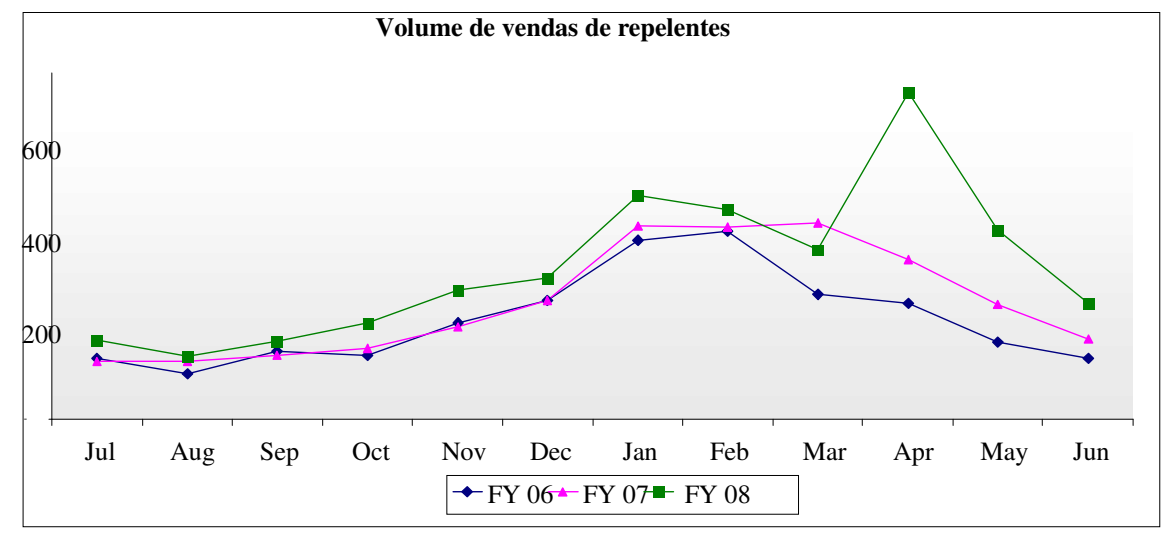

Fonte: Documentos internos da empresa DELTA

Uma demanda fora dos padrões não ocasiona apenas problemas de flutuação em vendas e participação de mercado decorrentes da falta de estoque; vários outros aspectos do negócio são igualmente afetados. Na mídia, falta espaço para que os players do mercado de inseticidas anunciem seus produtos, já que todos querem aproveitar o momento. Como consequiência imediata dessa disputa por espaço publicitário, forma-se um enorme ruído de comunicação que acaba impedindo que os consumidores diferenciem os produtos uns dos outros. A disputa por espaços de exibição dos produtos nas gôndolas de supermercados e farmácias também acabou prejudicando a marca líder, que perdeu visibilidade para as marcas menores em uma oportunidade em que era crucial destacar-se frente aos potenciais consumidores.

A partir do surto de dengue no verão de 2007/2008, o mercado de controle de pragas urbanas cresceu substancialmente, principalmente no que se refere à linha de repelentes, que ganhou mais relevância e penetração. Agora, depois que o verão da dengue foi deixado para trás pelas baixas temperaturas do inverno de 2008, inúmeros problemas e questionamentos apresentam-se para a DELTA. Novas marcas surgiram, novos concorrentes se estabeleceram. A direção da empresa alarmou-se com a dependência da companhia com relação a uma única categoria de produtos. As relações com os revendedores ficaram estremecidas em razão da escassez de repelentes. O desempenho da linha de produtos campeã de vendas da empresa mostrou forte relação com a ocorrência de uma doença relacionada com mudanças climáticas. 
Marina Dais de Faria \& José Luis Felicio dos Santos de Carvalho

A produção de inseticidas e repelentes evidenciou como ponto fraco um modelo de previsão de vendas incapaz de contemplar uma epidemia. Marcelo Roldan, Paulo Yotuel, Renata Ruzzo e suas equipes encontram-se diante de um quadro desafiador.

\subsection{De volta à sala de reuniões}

O grupo de marketing da companhia DELTA compreendia que a situação a eles apresentada envolvia aspectos estratégicos em marketing, vendas e produção, por mais que fosse tentador simplificar a questão ao que Renata havia dito, isto é, uma ocorrência de dengue resolveria quaisquer problemas de vendas da empresa. Mesmo porque o clima e a epidemia constituíam variáveis incontroláveis, e do ponto de vista gerencial era impossível considerar este imponderável como principal fator determinante do futuro da organização.

Em outras palavras, no curto prazo, passadas as perturbações devidas às enormes vendas da temporada anterior e à falta de estoque causada pela falha na previsão de demanda, era preciso planejar as ações para o verão de 2008/2009. Ademais, considerando as implicações para médio e longo prazos, as peculiaridades do verão da dengue tinham servido para alertar os diretores da empresa a repensar estrategicamente o próprio negócio.

Diante da análise da temporada 2007/2008, Marcelo e seus colegas haviam se convencido de que era preciso ter acesso a informações que pudessem melhorar a previsão de vendas realizada pela DELTA. Os dados referentes à previsão do tempo eram de extrema importância, assim como obter acesso prévio à ocorrência do fenômeno El Niño para os próximos anos. Mesmo no caso da disponibilidade de tais informações, Paulo tinha dúvidas de como se poderia estimar, por exemplo, como a ocorrência de dengue influenciaria nas vendas. Dados históricos evidenciavam a relação entre registros de casos da doença e vendas de inseticidas e repelentes. Contudo, qual seria o real impacto da doença nas vendas? Como negociar com os revendedores dos produtos da empresa sem conhecer tais variáveis?

Para Renata Ruzzo, mais difícil e importante do que tentar mensurar quanto o mercado seria afetado na presença de se novos casos de dengue era elaborar estratégias e planos de ação para temporadas sem dengue, pois a empresa precisa vender mesmo em anos nos quais a doença faça menos estragos. Como planejar para enfrentar os verões sem dengue, uma vez que as pessoas só parecem perceber a relevância da categoria perante a ameaça da doença?

Uma questão que vinha angustiando Marcelo era como lidar com a oportunidade de aumento de vendas em épocas de dengue sem que a empresa se apoiasse/ no infortúnio da sociedade para obter sucesso, ou seja, oferecendo seus produtos em consonância com 
Planejamento de cenários e amplificação da variabilidade da demanda

preceitos éticos valorizados pelo coletivo social. Marcelo entendia que tal questão era bastante complexa, e defendia que a empresa deveria investir para associar uma das marcas de inseticidas e a marca líder de repelentes ao controle da dengue. Nas palavras de Marcelo, essas marcas passariam a ser vistas como "aliadas da população contra a dengue". Renata, por sua vez, acreditava que é perda de dinheiro investir para vender os produtos da DELTA em uma época em que as vendas são impulsionadas pelo medo que as pessoas têm da doença. Para Paulo, o diretor de marketing, uma terceira opção seria trabalhar somente com a associação do repelente ao combate à dengue, já que a linha de repelentes é a mais afetada e a mais atrelada à doença.

Outra questão a ser definida para a elaboração dos planos para a próxima temporada dizia respeito a como seriam trabalhadas linhas de produtos e as marcas da empresa nas próximas temporadas. Até o verão de 2007/2008, as marcas correspondiam às unidades estratégicas de negócio (UENs). No entanto, como as pesquisas revelaram expressivas diferenças entre as linhas de produtos, no que tange a penetração, freqüência de compra e perfil dos consumidores, Paulo Yotuel passou a defender que sejam trabalhadas as linhas de produtos como UENs. Cada uma das linhas de produtos exerce um papel diferente no combate às pragas, e tais aspectos poderiam ser melhor explorados do que são atualmente, em função de a configuração presente exigir unidade entre os produtos da mesma marca, independentemente de serem apresentados sob a forma de aerossol ou elétricos, por exemplo. Uma adaptação da estratégia para linhas de produtos exigiria mudanças correspondentes na estrutura das divisões de marketing e vendas, já que a empresa trabalhava atualmente com gerenciamento por marcas.

Ao término da reunião, ao final de mais uma tarde sem almoço, Marcelo Roldan compreendeu que as discussões haviam suscitado mais perguntas do que respostas, o que era de se esperar em função da natureza do problema. Ao menos parecia a Marcelo que todos os membros da divisão de marketing da DELTA compartilhavam da opinião de que o verão da dengue tinha sido capaz de despertar a organização para a necessidade de mudanças em diversos setores e áreas além de marketing e vendas, tais como estratégia e produção. O verão de 2008/2009 batia às portas da DELTA e, por ora, o estranho zumbido permaneceria. 
Marina Dais de Faria \& José Luis Felicio dos Santos de Carvalho

\section{Anexo - Notas de ensino}

\subsection{Resumo do caso}

Na temporada de verão de 2007/2008, uma epidemia de dengue fez com que aumentassem as vendas de inseticidas e disparassem as de repelentes. Falhas na previsão de um crescimento tão expressivo nas vendas provocaram o desaparecimento de repelentes nas prateleiras de supermercados e farmácias, o que acabou prejudicando a líder de mercado DELTA e a vicelíder GAMA, que perderam parte de sua participação para marcas alternativas produzidas por pequenas empresas. Passado o período crítico, a gerente de vendas da DELTA, Renata Ruzzo, bem como Marcelo Roldan, gerente de marcas e Paulo Yotuel, diretor de marketing, estão reunidos com suas equipes para decidir quais serão as estratégias a serem seguidas pela empresa e por suas marcas para o próximo verão. Analisando as planilhas com dados históricos que apontam que as vendas dos produtos da DELTA são afetadas pela dengue, e revendo estudos acerca dos perfis de consumidores de cada uma das linhas de produtos para controle de pragas, surgem novos questionamentos para os integrantes da divisão de marketing da empresa. Como explorar mais efetivamente cada linha de produtos? Como prever a ocorrência de dengue no próximo verão? Que estratégias usar no caso de um novo surto? Como retomar as relações com os revendedores depois de uma temporada caótica? E na hipótese de uma temporada livre de mosquitos, como sobreviver a um verão sem dengue?

\subsection{Fontes de dados}

O presente caso para estudo foi elaborado em consonância com as recomendações de Graham e Cline (1980), Leenders e Erskine (1989) e Roesch (2007). Os dados apresentados no caso são reais; apenas os nomes das empresas e dos personagens envolvidos foram modificados. Os dados acerca da febre dengue, sobre as ocorrências epidêmicas no Brasil e a respeito do combate à doença pelo Estado foram compilados a partir de pesquisas conduzidas por Coelho et al. (2008), Costa et al. (2008), Ramos (2008) e Torres (2008). Alguns dados foram complementados por informações obtidas no sítio eletrônico do Ministério da Saúde.

Os dados empíricos foram coletados principalmente por meio de investigação documental, conforme sugerem Graham e Cline (1980). A pesquisa documental costuma valer-se de documentos conservados no interior de órgãos públicos e privados, que ainda não receberam qualquer tratamento analítico, ou documentos que de algum modo já sofreram algum tipo de análise, tais como demonstrativos contábeis e relatórios de vendas (GIL, 2008; VERGARA, 2009). Na presente pesquisa, foram usadas apresentações com resultados de pesquisas 
Planejamento de cenários e amplificação da variabilidade da demanda

encomendadas pela empresa, planilhas de vendas dos produtos da DELTA e do mercado como um todo nos últimos anos, e relatórios sobre estoques e capacidade de produção.

Outra técnica de coleta de dados para a construção do caso foi a observação direta do tipo participante (SAMPIERI, COLLADO \& LUCIO, 2006), por meio da qual um dos autores do presente texto engajou-se em ações de marketing empreendidas pela empresa DELTA no período imediatamente posterior à epidemia de dengue da temporada 2007/2008. Em tais ações, houve envolvimento em reuniões e atividades de planejamento de marketing, campanhas de propaganda e promoção e ações de vendas.

\subsection{Objetivos educacionais}

O caso apresenta-se de modo a discutir conceitos fundamentais em Administração, com envolvimento de diversos aspectos do negócio e de várias áreas da organização, com ênfase nas questões éticas envolvidas nas atividades da DELTA e de seus concorrentes. Recomendase, outrossim, que o caso seja preferencialmente utilizado em cursos de graduação ou em matérias básicas de programas de pós-graduação. Nos primeiros estágios do aprendizado acadêmico, o enfoque deve contemplar a descoberta e a inventividade dos estudantes (ARGYRIS, 1980), e acredita-se que o caso da DELTA favoreça tais possibilidades.

A utilização de casos para estudo em cursos de graduação deve acomodar interpretações diversas, diferentes modos de estruturar os problemas levantados pela apresentação dos dados e contemplar possibilidades ricas de aproveitamento de teorias, buscando reproduzir a complexidade e as dificuldades do mundo organizacional (BOOTH et al., 2000). De acordo com essa diretriz, o caso parece ser primordialmente adaptável às disciplinas de Administração Estratégica, Fundamentos de Marketing e Administração da Produção. Em função dos questionamentos sobre conflitos entre interesses da organização e bem-estar social, o caso pode igualmente ser aproveitado em cursos de Ética para Administração.

De modo sucinto, o caso lida basicamente com quatro grandes vertentes de aprendizagem no que concerne aos conceitos fundamentais para estudantes de Administração. Em primeiro lugar, a compreensão do imperativo ambiental e a aceitação da incerteza como elementos determinantes para o planejamento das atividades de organizações (SCHERMERHORN Jr., 2007). Segundo, a percepção de estratégia como processo de transformação capaz de permitir o desenvolvimento de uma organização (MINTZBERG, AHLSTRAND \& LAMPEL, 2000). Em terceiro lugar, a importância da integração entre áreas e funções de uma organização para permitir uma resposta efetiva aos desafios do mercado (GALBRAITH \& LAWLER III, 
Marina Dais de Faria \& José Luis Felicio dos Santos de Carvalho

1995). Finalmente, a necessidade de se considerar o respeito à ética como condição fundamental para a ação empresarial (SROUR, 2000).

Os autores do presente texto recomendam que quaisquer iniciativas de uso de casos para estudo sejam precedidas pela leitura de trabalhos críticos acerca do aproveitamento do método em salas de aula. Para Argyris (1985), por exemplo, algumas conseqüências deletérias da utilização de casos para estudo incluem: (1) ignorar questões importantes para os alunos, mas que o professor tenha deixado passar; (2) incentivar um clima de competição, de modo que vencer seja mais importante que aprender; (3) permitir que os estudantes distorçam dados com o intuito de resolver mais efetivamente o problema; e (4) aumentar a dependência dos alunos com relação à figura de um instrutor para enfrentar as questões que lhes forem impostas. Para Faria e Carvalho (2005), casos são representações dramatúrgicas que têm o poder de iludir/convencer com base na autoridade concedida à alta hierarquia e às grandes empresas, e que acabam por impedir a emergência de representações mais plurais e democráticas.

\subsection{Aplicação do caso}

Como se viu na seção anterior, os autores crêem que este caso apresenta maiores possibilidades de aproveitamento em disciplinas de Estratégia, Marketing, Produção e Ética. Os temas listados a seguir constituem alternativas não-exclusivas de aplicação; as referências correspondentes podem dar suporte às discussões em classe.

No âmbito da Administração Estratégica, tem-se no caso DELTA uma chance de discussão de conceitos elementares como visão empresarial e declaração de missão - ambos ausentes no texto e, por isso mesmo, passíveis de debate - complementada por uma análise SWOT, conforme as premissas da escola do design em estratégia (MINTZBERG, AHLSTRAND \& LAMPEL, 2000). O texto abre a possibilidade de se recorrer a análises SWOT não convencionais, como a desenvolvida por Valentin (2001), que aplica o modelo segundo a visão baseada em recursos. O caso presta-se sobremaneira à discussão de um conceito central para o planejamento estratégico: a construção de cenários diante de diversos futuros possíveis - verão sem dengue, com poucos casos, com epidemia -, exemplificando o uso de instrumento criado para lidar com a incerteza ambiental (JOHNSTON, GILMORE \& CARSON, 2008). O caso também sugere boas chances de testar a compreensão pelos alunos do principal esquema de Michael Porter (2004) para análise competitiva: a análise estrutural da indústria por meio do "modelo das cinco forças". Outro tópico suscitado pelo caso é o impacto das escolhas estratégicas no desempenho de organizações (p. ex.: CAMELO, 2008). 
Planejamento de cenários e amplificação da variabilidade da demanda

Na instância de Marketing, o caso da DELTA pode proporcionar uma oportunidade para debater o problema da quantidade adequada de itens no portfólio de uma empresa no que diz respeito a amplitude, extensão e profundidade (ver BORDLEY, 2003). Tal debate pode conduzir à discussão sobre as marcas da DELTA, especificamente no que se refere ao posicionamento das marcas, à seleção dos canais para cada uma delas, às estratégias de comunicação para as marcas, ao papel do desempenho dos produtos e de seus atributos tangíveis e intangíveis para a imagem da marca e à experiência percebida pelos clientes com a marca (KELLER \& LEHMANN, 2006). Outro tópico pode envolver a elaboração de campanhas de comunicação para os produtos da DELTA levando em conta que tradicionalmente a propaganda comprada pelos players do setor costuma amparar-se no problemático retrato da mulher como "dona-de-casa", conforme alertam há décadas pesquisadores da área (p. ex.: LEIGH, RETHANS \& WHITNEY, 1987).

As dificuldades em determinar a demanda de produtos de controle de pragas urbanas pelos executivos da DELTA e de seus concorrentes oferece uma oportunidade de explorar um tópico recorrente em Administração da Produção: o antigo porém atual problema da incerteza na previsão de vendas presente em diversas organizações (MOTTA, 1986; WALLACE, 2006). Esse problema se mostra ainda maior em empresas que trabalham com produtos que obedecem a sazonalidades nas vendas (cf. PIZZINATTO et al., 2007), como é o caso dos inseticidas e repelentes. Tomando por base a idéia de que a previsão de vendas interliga várias áreas e diversos processos da empresa (WALLACE, op. cit.), o caso da DELTA pode auxiliar também na aprendizagem dos temas da integração e da coordenação entre áreas de uma organização (MORASH, DRÖGE \& VICKERY, 1996; PAIVA \& SILVEIRA, 2004).

Este caso para estudo apresenta duas possibilidades para investigar temas de interesse da Ética. Primeiro, presta-se ao clássico debate acerca do confronto entre a perspectiva ética pragmática ou utilitarista versus os preceitos da ética deontológica (cf. BORGES, DALL'AGNOL \& DUTRA, 2002). Tal embate costuma servir como suporte para discutir o conceito de "egoísmo de mercado" (LYNCH, 2009), isto é, o argumento de que apesar de os agentes de mercado seguirem um interesse próprio não benevolente, tal posição é moralmente defensável e até mesmo moralmente requerida. Assim, alinhando-se à ética deontológica, em que se caracteriza a ação em função de ter sido praticada exclusivamente por dever, a DELTA trabalha com produtos que combatem o mosquito da dengue porque a sociedade precisa que a organização aja nesse sentido. De acordo com a ética utilitarista, cuja ênfase recai nas conseqüências das ações, os produtos da DELTA são feitos para trazer resultado positivo para 
Marina Dais de Faria \& José Luis Felicio dos Santos de Carvalho

o maior número possível de pessoas, incluindo os acionistas da empresa. A segunda questão a emergir com relevância para a ética refere-se ao âmbito da comunicação mercadológica (PRATT \& JAMES, 1994), especialmente às conseqüências de uma empresa privada elaborar campanhas de propaganda para vender produtos supostamente destinados a prevenir uma doença mortal que vem sofrendo combate por parte das instituições governamentais.

\subsection{Questões para discussão}

Os autores do presente texto endossam a idéia de que um caso para estudo não deve comportar a estruturação prévia de questões (cf. LEENDERS \& ERSKINE, 1989), e sugerem que não sejam apresentadas à turma perguntas que façam referência a aspectos específicos do caso. A determinação de questões a priori pode ensejar problemas e limitações, tais como: (1) restrição da atenção dos estudantes a alguns pontos, impedindo uma contemplação mais ampla dos temas presentes no caso; (2) a padronização de questões desconsidera diferenças no aprendizado de alunos e/ou turmas em estágios variados de conhecimento acerca dos temas.

Acredita-se que a tarefa de formulação das questões para discussão, se e quando isso se mostrar necessário, deva ficar aos cuidados dos próprios estudantes, haja vista que a elaboração de perguntas é parte fundamental da resolução de um caso, em conformidade com os preceitos pedagógicos que embasam o método. Ainda assim, respeitando a perspectiva de que há professores que preferem contar ao menos com uma orientação básica acerca de como conduzir a discussão de um caso, mostram-se aqui algumas possibilidades de perguntas. Por questões didáticas as perguntas serão apresentadas divididas nas três principais áreas nas quais ocaso pode ser utilizado: Marketing, Produção e Ética. Vale lembrar, entretanto, que os temas estão interligados.

\section{1- Marketing}

a) Diante das evidências de que a ocorrência de casos de dengue modifica o cenário de vendas de inseticidas e repelentes, que ferramentas deve utilizar a DELTA para estimar a configuração desse cenário?

b) Como deve ser feito o planejamento da empresa para que os gerentes de marketing possam ser capazes de lidar com qualquer um dentre os três cenários (ausência de dengue; surto médio de dengue; epidemia de dengue) que possam ocorrer nas próximas temporadas?

c) O caso mostrou as várias diferenças existentes entre as linhas de produtos das categorias de repelentes e inseticidas. Devem ser revistas as UENs da DELTA? Como trabalhar as estratégias de marketing das diferentes linhas de produtos da empresa, independentemente do 
Planejamento de cenários e amplificação da variabilidade da demanda

aparecimento de casos de dengue?

2- Produção

a) Tendo em vista a expressiva sazonalidade de inseticidas e repelentes, qual seria a melhor maneira de adequar a capacidade de produção às estimativas de demanda?

b) Como deve ser feito o planejamento tático da área de operações para que a empresa possa ser capaz de lidar com qualquer um dentre os três cenários (ausência de dengue; surto médio de dengue; epidemia de dengue) que possam ocorrer nas próximas temporadas?

3- Ética

a) Devido à relação direta entre o aumento dos casos de dengue e o aumento do volume de vendas de repelentes e inseticidas, surge a preocupação dos gestores da DELTA em vincular o nome da empresa ao combate a dengue sem que isso pareça oportunismo. Quais princípios éticos devem ser seguidos?

\section{REFERÊNCIAS}

ARGYRIS, C. Some limitations of the case method: experiences in a management development program. The Academy of Management Review, v. 5, n. 2, 1980. p. 291-298.

BOOTH, C.; BOWIE, S.; JORDAN, J.; RIPPIN, A. The use of the case method in large and diverse undergraduate business programmes: problems and issues. The International Journal of Management Education, v. 1, n. 1, 2000. p. 62-75.

BORDLEY, R. Determining the appropriate depth and breadth of a firm's product portfolio. Journal of Marketing Research, v. 40, n. 1, feb. 2003, p. 39-53.

BORGES, M.; DALL’AGNOL, D.; DUTRA, D. Ética. Rio de Janeiro: DP\&A, 2002.

CAMELO, S. Associações entre estratégia competitiva e desempenho: um panorama de grandes empresas no Brasil. In: ENCONTRO DA ASSOCIAÇÃO NACIONAL DOS PROGRAMAS DE PÓS-GRADUAÇÃO EM ADMINISTRAÇÃ̃O, 32. Anais... Rio de Janeiro: Anpad, 2008.

COELHO, G.; BURATTINI, M.; TEIXEIRA, M.; COUTINHO, F.; MASSAD, E. Dynamics of the 2006/2007 dengue outbreak in Brasil. Memórias do Instituto Oswaldo Cruz, v. 103, n. 6, set. 2008. p. 535-540.

COSTA, F.; SILVA, J.; SOUZA, C.; MENDES, J. Dinâmica populacional de Aedes aegypti (L) em área urbana de alta incidência de dengue. Revista da Sociedade Brasileira de 
Marina Dais de Faria \& José Luis Felicio dos Santos de Carvalho

Medicina Tropical, v. 41, n. 3, mai.-jun. 2008. p. 309-312.

FARIA, A.; CARVALHO, J. Casos em estratégia como representações dramatúrgicas. In: ENCONTRO DE ESTUDOS EM ESTRATÉGIA, 2. Anais... Rio de Janeiro: Anpad, 2005.

GALBRAITH, J.; LAWLER III, E. Organizando para competir no futuro: estratégia para gerenciar o futuro das organizações. São Paulo: Makron, 1995.

GIL, A. Métodos e técnicas de pesquisa social. 6 ed. São Paulo: Atlas, 2008.

GRAHAM, P.; CLINE, P. The case method: a basic teaching approach. Theory Into Practice, v. 19, n. 2, Spring 1980. p. 112-116.

JOHNSTON, M.; GILMORE, A.; CARSON, D. Dealing with environmental uncertainty: the value of scenario planning for small to medium-sized entreprises (SMEs). European Journal of Marketing, v. 42, n. 11/12, 2008. p. 1170-1178.

KELLER, K.; LEHMANN, D. Brands and branding: research findings and future priorities. Marketing Science, v. 25, n. 6, nov.-dec. 2006. p. 740-759.

LEENDERS, M.; ERSKINE, J. Case research: the case writing process. 3. ed. London: The University of Western Ontario, 1989.

LEIGH, T.; RETHANS, A.; WHITNEY, T. Role portrayals of women in advertising: cognitive responses and advertising effectiveness. Journal of Advertising Research, v. 27, n. 5, oct.-nov. 1987. p. 54-63.

LYNCH, T. Legitimating market egoism: the availability problem. Journal of Business Ethics, v. 84, n. 1, jan. 2009. p. 89-95.

MINTZBERG, H.; AHLSTRAND, B.; LAMPEL, J. Safári de estratégia: um roteiro pela selva do planejamento estratégico. Porto Alegre: Bookman, 2000.

MORASH, E.; DRÖGE, C.; VICKERY, S. Boundary spanning interfaces between logistics, production, marketing and new product development. International Journal of Physical Distribution \& Logistics Management, v. 26, n. 8, 1996, p. 43-62.

MOTTA, J. Como reduzir a incerteza em previsões de vendas. Revista de Administração de Empresas, v. 26, n. 1, jan.-mar. 1986. p. 25-42.

PAIVA, E.; SILVEIRA, T. Integration between manufacturing and marketing: still a missing link? In: ENCONTRO NACIONAL DA ASSOCIAÇÃO NACIONAL DOS PROGRAMAS DE PÓS-GRADUAÇÃO EM ADMINISTRAÇÃO, 28. Anais... Curitiba: Anpad, 2004. 
PIZZINATTO, N.; SPERS, E.; FARAH, O.; NEVES, M. Um método para previsão de vendas cumulativas por intervalo em promoções de bens de consumo. Revista de Administração da Universidade de São Paulo, v. 42, n. 3, jul.-set. 2007. p. 363-372.

PORTER, M. Estratégia competitiva: técnicas para análise de indústrias e da concorrência. 16. ed. Rio de Janeiro: Campus, 2004.

PRATT, C.; JAMES, E. Advertising ethics: a contextual response based on classical ethical theory. Journal of Business Ethics, v. 13, n. 6, jun. 1994. p. 455-468.

RAMOS, E. Hemoterapia e febre dengue. Revista Brasileira de Hematologia e Hemoterapia, v. 30, n. 1, 2008. p. 61-69.

ROESCH, S. Notas sobre a construção de casos para ensino. Revista de Administração Contemporânea, v. 11, n. 2, abr.-jun. 2007. p. 213-234.

SAMPIERI, R.; COLLADO, C.; LUCIO, P. Metodologia de pesquisa. 3. ed. São Paulo: McGraw-Hill, 2006.

SCHERMERHORN Jr., J. Management. 9. ed. New York: John Wiley \& Sons, 2007.

SROUR, R. Ética empresarial: posturas responsáveis nos negócios, na política e nas relações pessoais. Rio de Janeiro: Campus, 2000.

TORRES, E. Dengue. Estudos Avançados, v. 22, n. 64, 2008. p. 33-52.

VALENTIN, E. SWOT analysis from a resource-based view. Journal of Marketing Theory \& Practice, v. 9, n. 2, Spring 2001. p. 54-68.

VERGARA, S. Projetos e relatórios de pesquisa em Administração. 10. ed. São Paulo: Atlas, 2009.

WALLACE, T. Forecasting and sales \& operations planning: synergy in action. The Journal of Business Forecasting, Spring 2006. p. 14-36. 